NASA Technical Memorandum 4498

\title{
Strain Sensing Technology for High Temperature Applications
}

W. Dan Williams

Lewis Research Center

Cleveland, Ohio

\section{NMSA \\ National Aeronautics and Space Administration \\ Office of Management \\ Scientific and Technical Information Program




\title{
STRAIN SENSING TECHNOLOGY FOR HIGH TEMPERATURE APPLICATIONS
}

\author{
W. Dan Williams \\ National Aeronautics and Space Administration \\ Lewis Research Center \\ Cleveland, Ohio
}

\section{Summary}

This review paper discusses the status of strain sensing technology for high temperature applications. Technologies covered are those supported by NASA such as required for applications in hypersonic vehicles and engines, advanced subsonic engines, as well as material and structure development. The applications may be at temperatures of $540^{\circ} \mathrm{C}$ $\left(1000^{\circ} \mathrm{F}\right)$ to temperatures in excess of $1400^{\circ} \mathrm{C}\left(2500^{\circ} \mathrm{F}\right)$. The most promising technologies at present are the resistance strain gage and remote sensing schemes. Resistance strain gages discussed include the BCL gage, the LaRC compensated gage, and the $\mathrm{PdCr}$ gage. Remote sensing schemes such as laser based speckle strain measurement, phase-shifting interferometry and $\mathrm{x}$-ray extensometry will be discussed. Present status and limitations of these technologies are presented.

\section{Introduction}

High temperature strain measurements are needed for engine testing and for airframe structure testing. Strain measurements in the hot section of gas turbine engines are routinely difficult because of high temperatures and the harsh environment. Temperatures in excess of $1000^{\circ} \mathrm{C}\left(1800^{\circ} \mathrm{F}\right)$ are common in present commercial engines. Strain measurements in advanced subsonic engines and ramjet and scramjet engines for hypersonic vehicles promise to be even more challenging owing to higher temperatures. Airframe structures and test panels of advanced aircraft such as the National Aerospace Plane (NASP) are expected to see temperatures comparable to or less than those of present commercial engines. Stagnation temperatures on leading edges of titanium matrix composites (TMC) structures may approach $800^{\circ} \mathrm{C}\left(1500^{\circ} \mathrm{F}\right)$. Materials for all these programs must be developed and tested in the laboratory at use temperatures with strain sensing techniques. However, all these temperatures are difficult for strain sensing techniques.

At these higher temperatures no commercial static strain sensing technology is available. Commercial resistance strain gages do not demonstrate repeatable resistance values at elevated temperatures in excess of about $400^{\circ} \mathrm{C}\left(750^{\circ} \mathrm{F}\right)$. The resistance of a strain gage must be independent of the time at temperature, that is, drift free. No reliable remote strain measurement technique has been sufficiently demonstrated for commercial application. The following is a discussion of the technology being addressed by NASA for programs such as the NASP.

\section{Resistance Strain Gages}

Resistance strain gage strain measurement is accomplished by measuring the fractional change in resistance $\Delta R / R$ of a material such as a fine wire or thin film. The magnitude of $\Delta R / R$ is proportional to strain as given by

$$
\Delta R / R_{o}=\Delta \varepsilon G
$$

where $\Delta \varepsilon$ is the applied strain and $G$ is the gage factor. The change in resistance is caused by the piezoresistive and size variation effects of the gage material. Unfortunately, the resistance of gage material is also sensitive to the rate of change in temperature $T$, and often, time $t$, when the gage is at elevated temperatures.

For high temperature strain gages, the change in resistance with $T$ and $t$ is difficult to control. Because the effect can be much larger than that from strain alone, the additional effect must be subtracted. The operative equation is

$$
\begin{aligned}
\Delta \varepsilon_{\text {true strain }} & =\left[\left(\Delta R_{\varepsilon, T, t} / R_{o}\right)-\left(\Delta R_{T, t} / R_{o}\right)\right] / G \\
& =\Delta \varepsilon_{\text {total strain }}-\Delta \varepsilon_{\text {apparent strain }}
\end{aligned}
$$

The first term represents the measured or total strain and the second term represents the apparent strain also called thermal output. The apparent strain must be used to correct the measured strain to obtain the true strain. The correction may be difficult if the apparent strain is large compared to the true strain or is imprecisely known. It is for this reason that most commercial strain gages are limited in application to less than $400^{\circ} \mathrm{C}$

In Figure 1 we show the apparent strain as a function of temperature for four high temperature resistant strain gages which are being developed. These four gages are the most promising high temperature gages because they have some of the more desirable characteristics. The Chinese $700^{\circ} \mathrm{C}$ and 


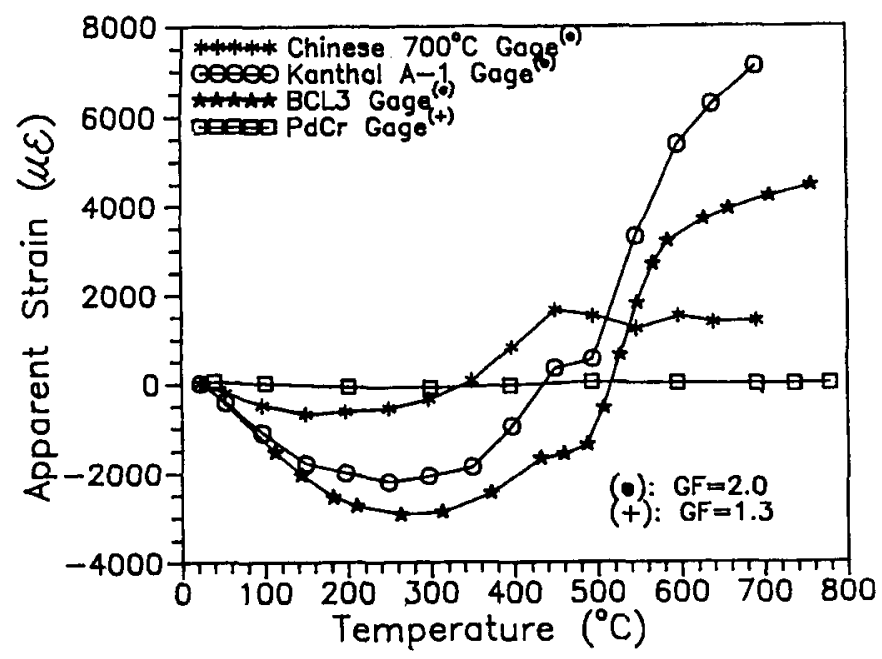

Figure 1. - Apparent strain versus temperature for four high temperature resistance strain gage materials. $\mathrm{PdCr}$ gage factor 1.3 , others 2.0 .

the $\mathrm{PdCr}$ alloy gages are temperature compensated. Other characteristics include relatively stable resistance and freedom from oxidation. However, these gages are not without difficulty. As can be seen in Figure 1 there is significant apparent strain for three of the gage materials; Chinese $700^{\circ} \mathrm{C}$, Kanthal A-1, and BCL. For typical applications of measurement of $2000 \mu \varepsilon$ (microstrain) for example, the large magnitude of the apparent strain on the order of several thousand makes accurate subtraction difficult. It is for this reason that present research is toward developing compensation schemes to reduce or eliminate the apparent strain. Furthermore, if the temperature is not precisely known then any error in the temperature measurement will result in an error in the apparent strain value which is used in the subtraction.

The apparent strain is also related to the differences in temperature coefficient of expansion (TCE) between the substrate material or test material and that of the gage material. Palladium chrome (PdCr) has low apparent strain after compensation. The compensation technique used for $\mathrm{PdCr}$ and the Chinese $700{ }^{\circ} \mathrm{C}$ minimizes the effect of TCE differences. However, because $\mathrm{PdCr}$ has a linear temperature coefficient of resistance (TCR) its apparent strain can be more nearly eliminated than that of Chinese $700{ }^{\circ} \mathrm{C}$. The Chinese $700{ }^{\circ} \mathrm{C}$ alloy and other FeCrAl based gages, such as Kanthal A-1 and BCL, have very nonlinear TCR's.

This situation is further complicated by the addition of a time variation or drift of the apparent strain curves of FeCrAl gages. This drift magnitude can be several thousand microstrain in a few hours. Therefore, knowledge of the apparent strain curve may be of limited value if it is not reliable and is not thoroughly repeatable. Other complications for many strain gages are the unfortunate problem for $\mathrm{FeCrAl}$ gages of a variation of apparent strain with heating and cooling rates. Differences in cooling at $10^{\circ} \mathrm{C}$ per minute or $1{ }^{\circ} \mathrm{C}$ per minute may result in significant shifts of the apparent strain value at room temperature.

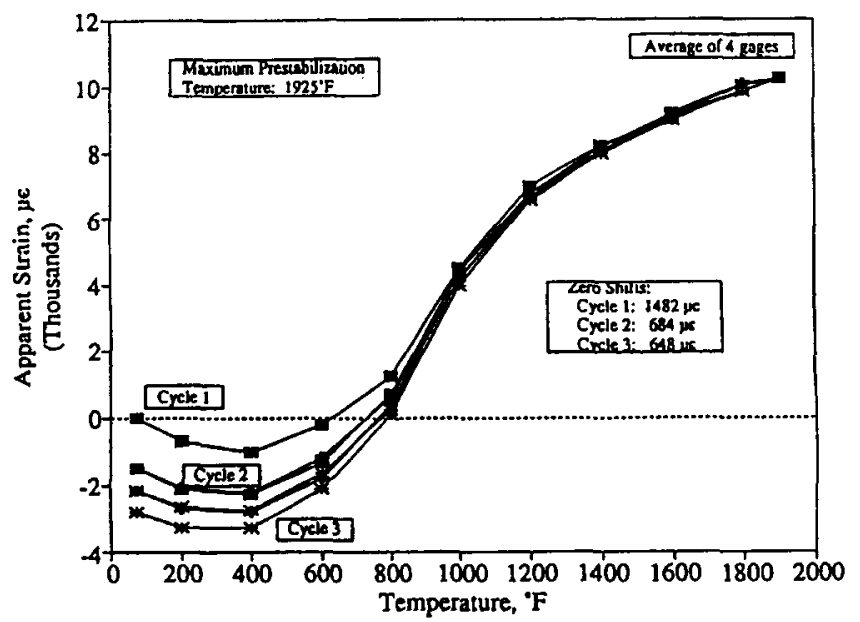

Figure 2. - Average apparent strain versus temperature for $\mathrm{BCL}$ gage. Note that the anchor point at high temperature does not prevent apparent strain variation at low temperature. (Used by permission of M.M. Lemcoe, PRC, Inc.)

The following is a discussion of the three most promising gages being developed under the NASP program. BCL is a standard gage which is being developed by NASA Ames Dryden Flight Research Facility. A new gage design by NASA Langley Research Center is referred to as the LaRC compensated gage. The gage material selected for the LaRC compensated gage is an $\mathrm{FeCrAl}$ material, as is the $\mathrm{BCL}$ gage. Finally, the PdCr gage is being developed at NASA Lewis Research Center.

\section{BCL}

$\mathrm{BCL}$ is an FeCrAl based alloy which was originally developed by Battelle Columbus Laboratories under NASA Langley contract a number of years ago (refs. 1-3) (fig. 2). The apparent strain of a prestabilized (at $1050^{\circ} \mathrm{C}\left(1925^{\circ} \mathrm{F}\right)$ ) gage is fairly retraceable between $700^{\circ} \mathrm{C}\left(1200^{\circ} \mathrm{F}\right)$ and 1040 ${ }^{\circ} \mathrm{C}\left(1900^{\circ} \mathrm{F}\right)$. At lower temperatures zero shifts confuse the gage's use. The zero shifts at lower temperatures prevent the comparison of the gage's output with one heat up cycle with that of the following cool down cycle. However, the subsequent heat up cycle follows or retraces the previous cool down. Therefore the large apparent strain with temperature and zero shifts has made its application difficult.

Presently, NASA Dryden is developing this gage with compensation. Figure 3 shows a variation of the original $\mathrm{BCL}$ gage using a platinum compensator resistor fabricated into the center of the grid. The effect of this type of compensation is to rotate the apparent strain curve in figure 2 so that the end point, that is the high temperature apparent strain, is lower and closer to the starting value (fig. 4). It does not correct for TCE differences. This results in apparent strain compensation at room temperature and at high temperature. However, there is still significant apparent strain variation between the room temperature and maximum use temperature. Studies are also 


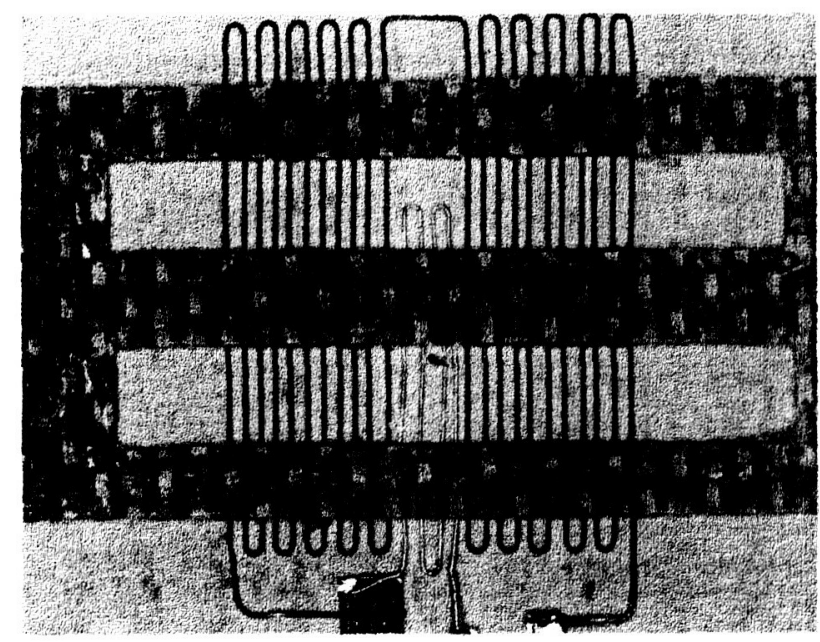

Figure 3. $-\mathrm{BCL}$ gage with $\mathrm{Pt}$ compensator resistor near the center of the gage. The Pt element is connected in series with the gage. (Used by permission of M.M. Lemcoe, PRC, Inc.)

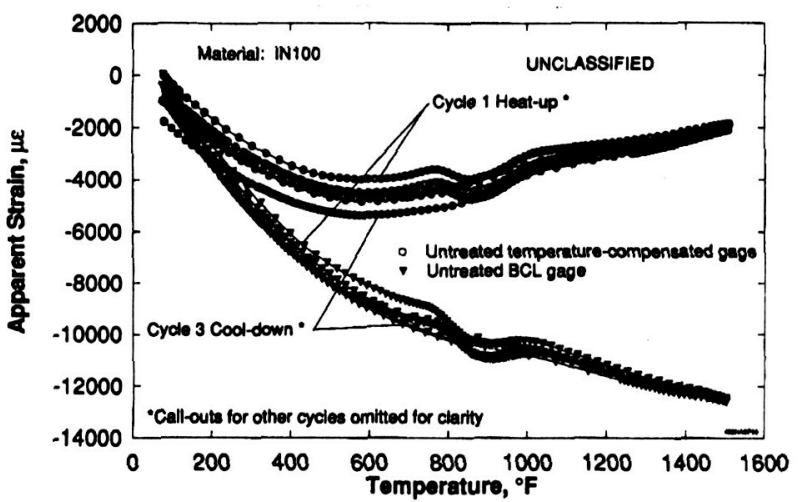

Figure 4. - Apparent strain versus temperature of BCL gage with Pt compensator and untreated standard gage. (Used by permission of M.M. Lemcoe, PRC, Inc.)

being performed at NASA Dryden (refs. 4 and 5) to determine the appropriate heat treatment for the gage before installation and thereby reduce cycle to cycle variation. This is owing to the requirement of recording of first cycle strain in the NASP program.

Gages manufactured from $\mathrm{FeCrAl}$ alloys, such as $\mathrm{BCL}$, Chinese $700{ }^{\circ} \mathrm{C}$ and Kanthal $\mathrm{A} 1$, undergo a metallurgical phase transition in the $400^{\circ} \mathrm{C}$ to $600^{\circ} \mathrm{C}\left(700\right.$ to $\left.1100^{\circ} \mathrm{F}\right)$ range. This transition has caused unusual problems with these types of gages. A detailed investigation of the BCL gage (ref. 6) was performed. This study demonstrated that the apparent strain of the gage is dependent on time at temperature as the gage is lowered through the phase transition temperature range. Furthermore, the speed with which the gage is brought through the phase transition temperature range also affects the

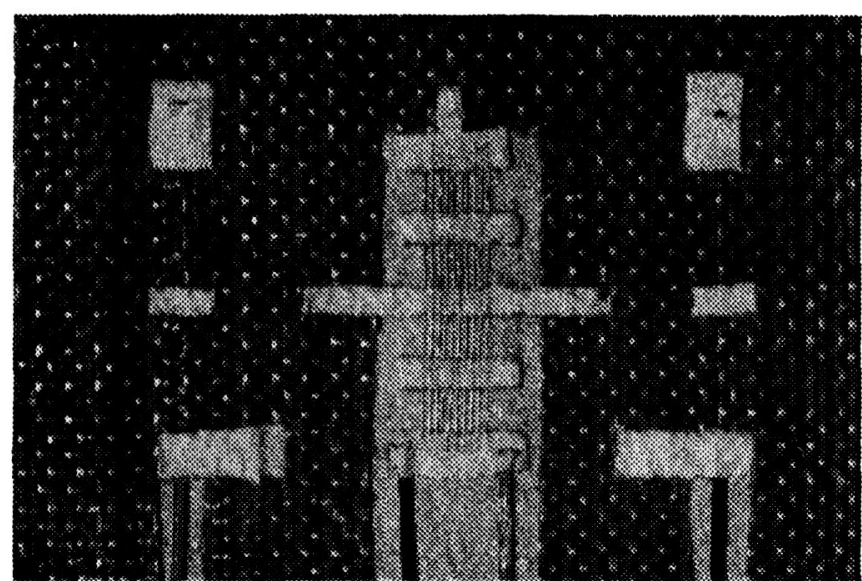

Figure 5. - The LaRC compensated gage using Chinese $700{ }^{\circ} \mathrm{C}$ alloy with compensator resistor of the same alloy around the periphery. The compensating element is connected in an adjacent arm of the bridge.

end point, or room temperature, apparent strain. Therefore, application of this gage may require a time at temperature history for each gage and each application.

\section{LaRC Compensated Gage}

The need for gage compensation has resulted in a new gage design at NASA Langley (ref. 7). This compensation technique utilizes two strain gages in one gage system. One gage is firmly attached to the material and measures the strain, while a second gage is free from the substrate material, and therefore, in theory, only senses the temperature in the region but not the strain. (fig. 5) The gages are then attached in a half bridge arrangement in adjacent arms. As long as the temperature coefficient of expansion of the substrate materials, or test article, and the gage material are similar then the apparent strain variation can be made quite small.

Figure 6 shows the installation of this gage on an IN750 coupon. The gage material selected for this demonstration was the $800^{\circ} \mathrm{C}$ Chinese alloy developed at Beijing Institute of Aeronautics and Astronautics (ref. 8). Other alloys could be used as well. Many of the difficulties experienced with gages of nonlinear TCR materials are overcome by the gage design. The apparent strain variation as a function of temperature is shown in figure 7 . Three consecutive runs were recorded. The apparent strain variation is small. The repeatability from cycle to cycle is quite good. The separation between the curves is artificially induced so the reproducibility can be easily demonstrated.

Figure 8 shows the apparent strain of this gage mounted on a TMC coupon and cycled to $760^{\circ} \mathrm{C}\left(1400^{\circ} \mathrm{F}\right)$. The apparent strain variation is as large as $5000 \mu \varepsilon$ but is reproducible to within $200 \mu \varepsilon$. The increase in apparent strain magnitude in figure 8 compared to figure 7 is a result of the TCE difference between the gage and the substrate material. The TCE of FeCrAl more nearly matches that of IN750, than that of TMC. 


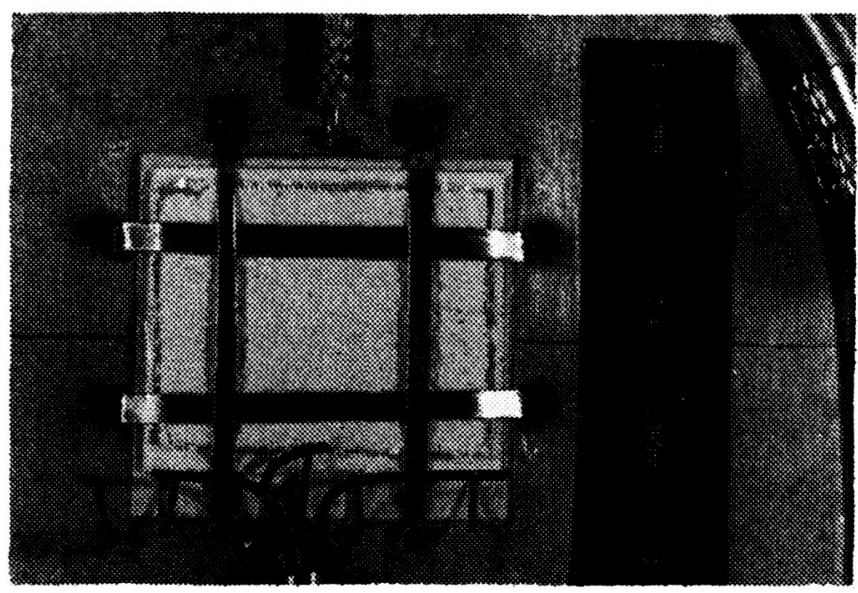

Figure 6. - Final assembly of the LaRC compensated gage. Nextel blanket acts as thermal barrier to have the compensator as close to the gage temperature as possible.

One Active Gage, One Compensation Gage Wired Together To Form A Half Bridge

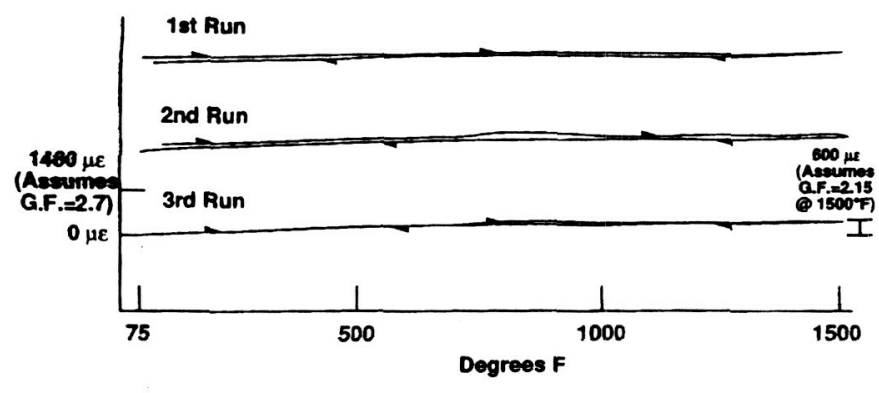

Figure 7. - Three apparent strain curves versus temperature of LaRC compensated gage on IN750. The curves are shifted to make them more visible.
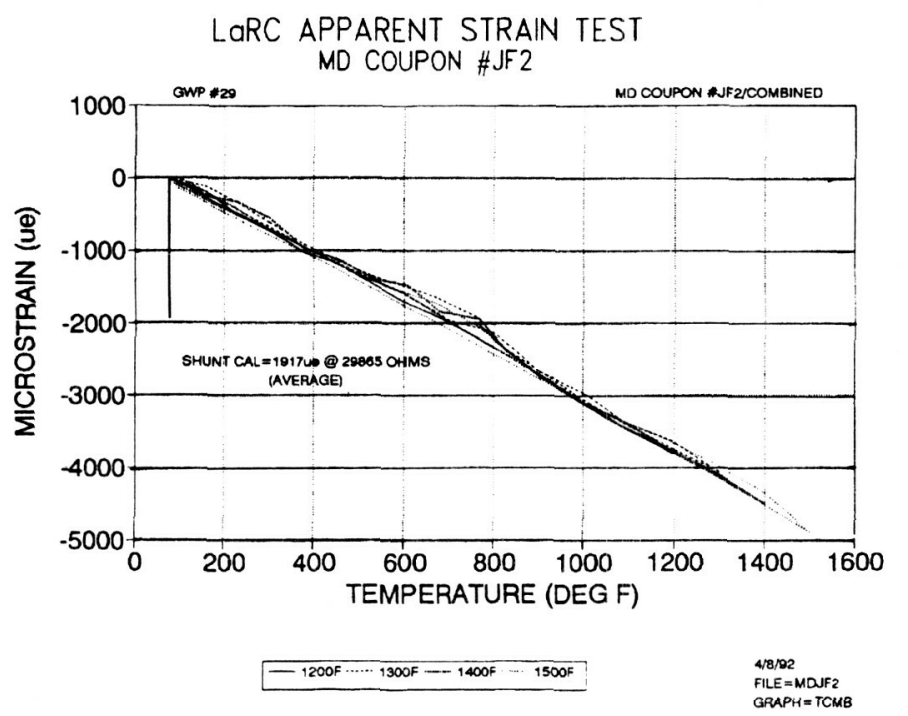

Figure 8. - Three apparent strain curves versus temperature of LaRC compensated gage on TMC.

\section{PdCr Gage}

PdCr gage has been developed at United Technologies Research Center for NASA Lewis Research Center with further refinements at NASA Lewis. The gage material is palladium and $13 \%$ (weight percent) chromium. This alloy was selected as a result of an exhaustive study (ref. 9) as having the most stable electrical properties among a number of alloys studied. The gage itself is fabricated with $\mathrm{PdCr}$ and a $\mathrm{Pt}$ compensating element (ref. 10). The gage and the compensator wires are both $1 \mathrm{mil}$ in diameter with $3 \mathrm{mil} \mathrm{PdCr}$ lead wires (fig. 9). This gage is connected in a half bridge arrangement with the compensator and ballast resistor in an adjacent arm of the bridge. This ballast resistor can be adjusted so that the gage can be compensated in such a way that the effect of the TCE mismatch between the gage material and the substrate is essentially eliminated. This technique also minimizes the large apparent strain associated with any gage material, but is successful only when the gage material has a linear resistance versus temperature curve.

The apparent strain variation verses temperature is given in figure 10. The apparent strain variation is about $1000 \mu \varepsilon$ and cycle to cycle variation of less than 200 up to $1470{ }^{\circ} \mathrm{F}$. As utilized in the present arrangement the wire is annealed before

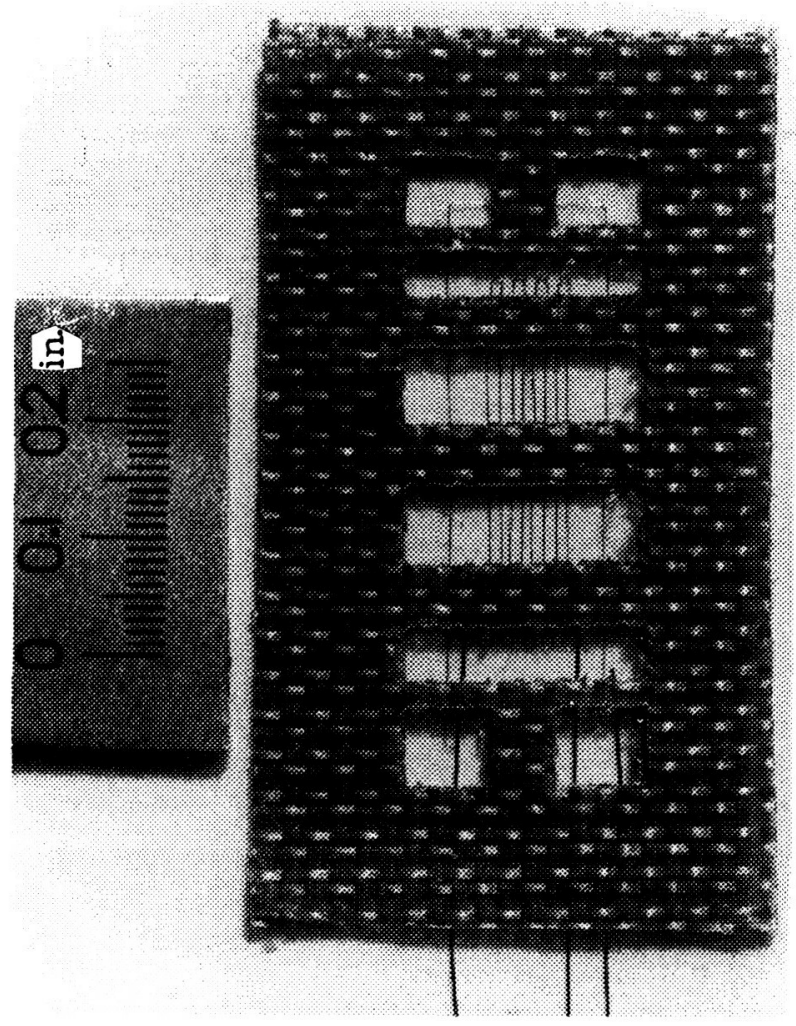

Figure 9. - A $\mathrm{PdCr} / \mathrm{Pt}$ temperature-compensated wire gage with the high temperature tape frame used for flame spray mounting. (Used by permission of J.-F. Lei, Sverdrup Technology, Inc.) 
installation to eliminate the need for thermal processing on the part and allowing first cycle data to be recorded. If the gage is stabilized on the test piece, a smaller apparent strain variation is possible.

A weldable version of this gage has been tested on TMC (fig. 11) and IN100 materials. The apparent strain versus

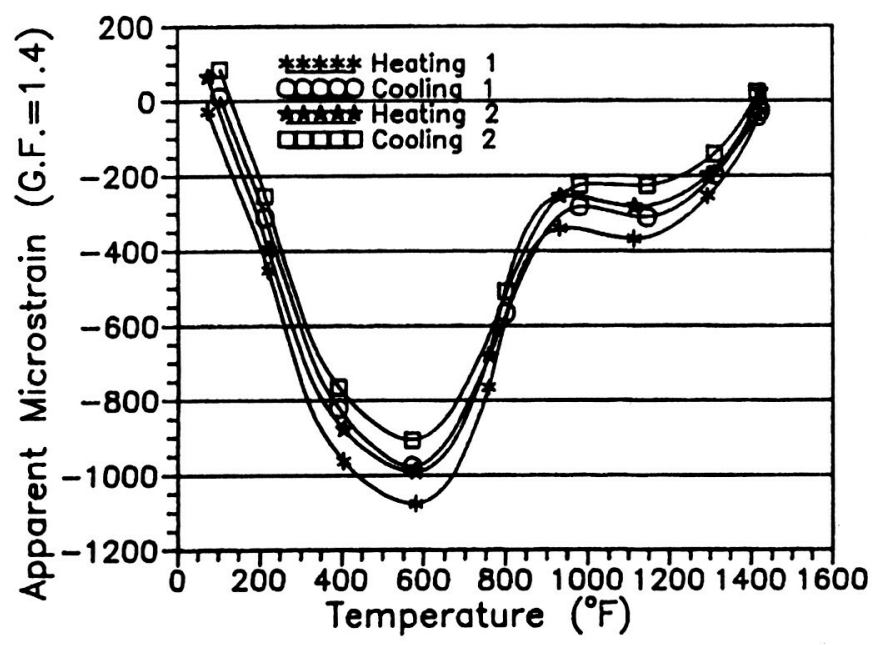

Figure 10. - Apparent strain vs temperature curves of a prestabilized $\mathrm{PdCr} /$ Pt wire gage during two thermal cycles to $1450^{\circ} \mathrm{F}$. The gage is installed on an IN100 coupon by flame-spray technique. Values of apparent strain of the gage are calculated assuming a constant gage factor of 1.4. (Used by permission of J.-F. Lei, Sverdrup Technology, Inc.)

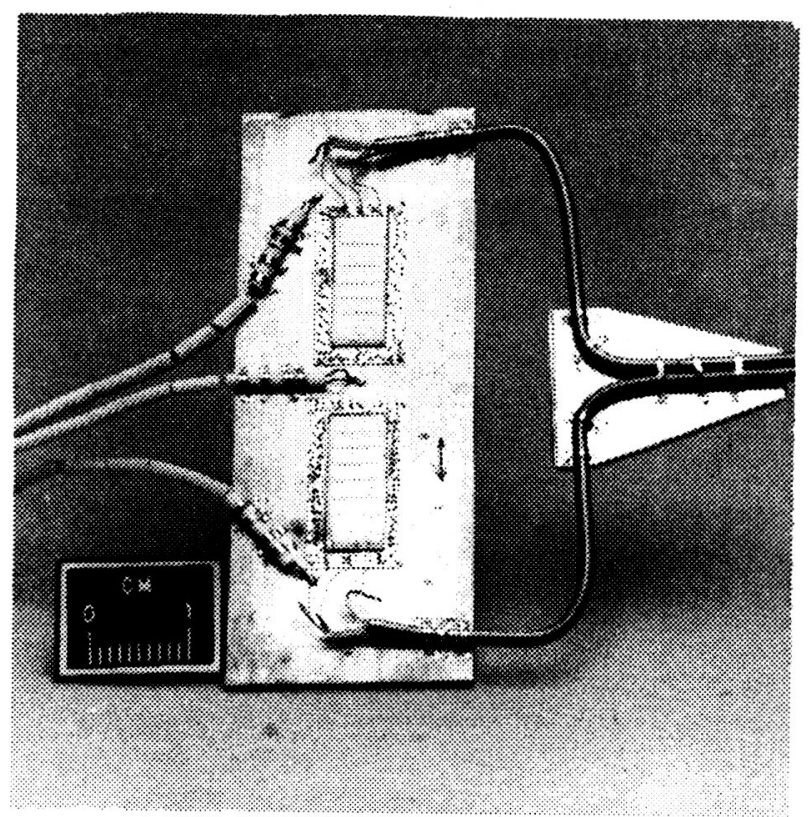

Figure 11. - Two weldable wire gages welded on a SCS-6/ß21-S titanium matrix composite (TMC) coupon. The gages are welded along the top fiber direction ( $\downarrow$ ). There are three thermocouples spot-welded on the coupon. (Used by permission of J.-F. Lei, Sverdrup Technology, Inc.) temperature for the IN100 mounted gage is essentially the same as that of the directly mounted gage. The situation is more complex with the TMC material. The apparent strain on TMC up to $650^{\circ} \mathrm{C}\left(1200^{\circ} \mathrm{F}\right)$ is similar to that on IN100, while above this temperature the apparent strain curves show significant hysteresis (fig. 12). The material was found to be permanently warped because of the temperature cycles.

\section{Remote Strain Sensing Schemes}

Remote strain measurement techniques have been investigated for many years due to their promise of advancements over resistance strain gages (ref. 11). The ability to measure strain by a technique which is noncontacting and nondestructive to the work piece is a major advancement in strain sensing technology. The maximum strain level measurable with a resistance strain gage is determined by the elastic properties of the strain gage or installation. Remote strain measurement, however, may be used into the plastic range of the test material. While resistance strain gages measure strain over a small area, in some cases optical techniques may be full field, that is measure the strain over the entire surface of the specimen. A resistance strain gage's output has to be corrected for apparent strain. Remote strain measurement systems also measure the thermal strain of the test material structure which then must be subtracted. However, at constant temperature there is no thermal effect or apparent strain which must be subtracted for both remote and resistance strain measurement systems.

High temperature remote strain sensing techniques are not without great difficulties. For many optical techniques the blackbody radiation from the specimen can mask the optical signal to be measured. Some remote strain sensing schemes require that a pattern or fiducial marks be attached to the surface or even notches cut into the test piece. Fabricating these can be complicated and in application of high temperatures the patterns and marks may be destroyed. The attachment of markers and/or grids sometimes requires modification of the surface. Modifications are usually discouraged or not permitted for some specimens such as composite materials. In addition to these problems, convection currents at the hot surface of the specimen may prevent maintaining the optical signal fidelity as the light interacts with the surface.

Advances in electronic computing, computer codes and optical and $\mathrm{x}$-ray based components have made possible advances in remote strain sensing schemes. Three approaches have been selected for development by NASA Lewis Research Center. These are: the laser speckle strain measurement system, phase-shifting holographic interferometry with Case Western Reserve University, and $x$-ray extensometry at the University of Connecticut. The following is a description of each of these techniques. 

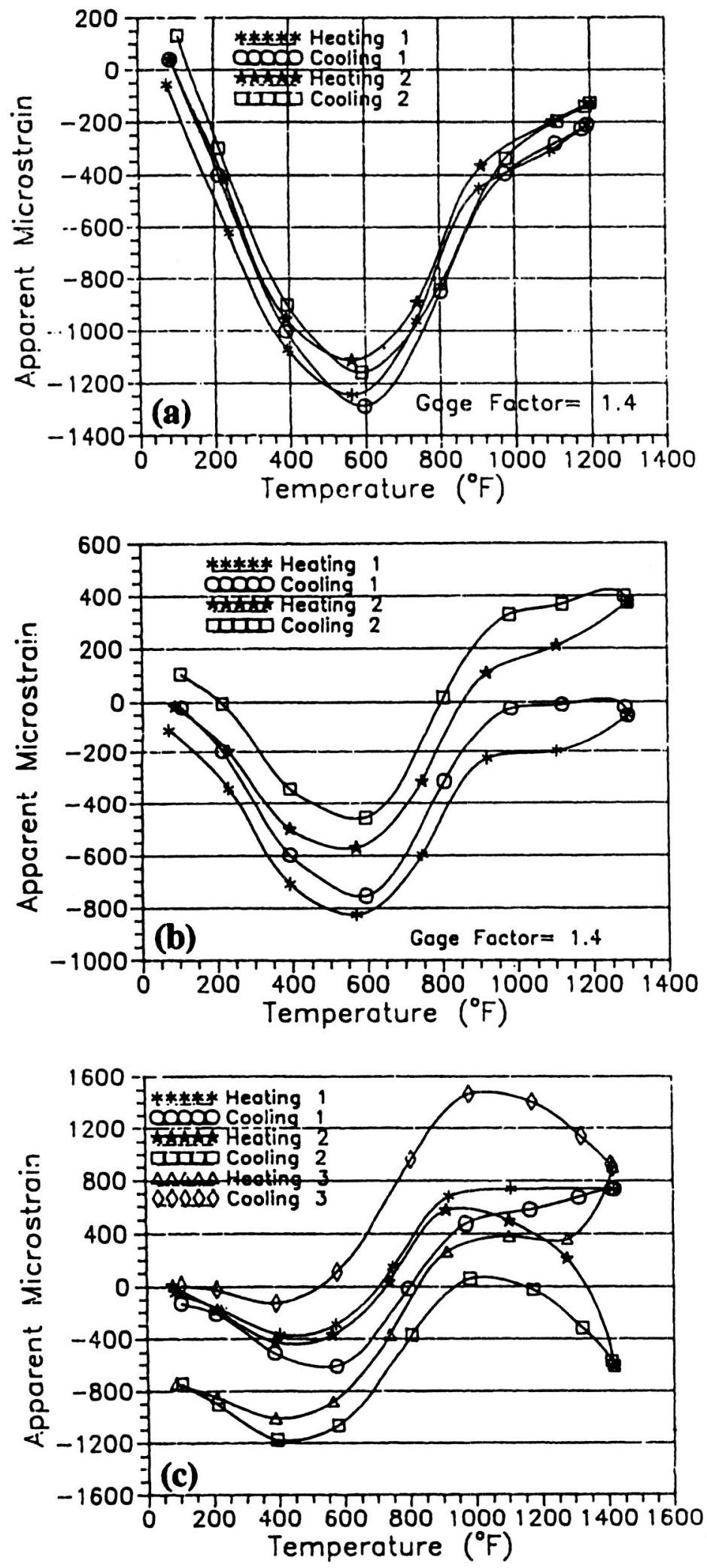

Figure 12. - Apparent strain vs temperature characteristics of a weldable wire gage during (a) two thermal cycles to $1200^{\circ} \mathrm{F}$, (b) two thermal cycles to $1300{ }^{\circ} \mathrm{F}$ and (c) three thermal cycles to $1420^{\circ} \mathrm{F}$. The gage is welded on a $0.025^{\prime \prime}$ thick TMC coupon. (Used by permission of J.-F. Lei, Sverdrup Technology, Inc.)

\section{Laser Speckle Strain Measurements}

Laser speckle strain measurement techniques for high temperature applications are being developed at the NASA Lewis Research Center. The concept is based on Yamaguchi's twobeam speckle strain measurement concept (ref. 12). This system automatically corrects for rigid body motion (ref. 13). The optical system is shown in figure 13. The system consists of an argon ion laser which can be alternately switched between an upper path and a lower path. Both the upper and lower paths of the beam intersect. the specimen at a angle less than $45^{\circ}$. The spot size where the two beams intersect determines the gage length, typically less than one millimeter.

The interaction of the two beams produces a speckled pattern which is recorded by a charge couple device (CCD) array camera. The speckle pattern consists of bright and dark areas as a result of constructive and destructive interference respectively at the specimen surface. The speckle pattern is related to the unique features on the specimen surface. If the surface were perfectly reflecting or specular no such speckled pattern would be formed. It is the imperfections on the surface that result in a speckled pattern, therefore no special surface preparation is required. As the specimen is strained the speckled pattern shifts following the deformation of the surface.

The out of plane motion or rigid body motion is eliminated by utilizing the two-beam approach. Starting with the upper beam, the process goes as follows: the upper beam specklegram is recorded, the lower beam specklegram is recorded, the specimen is strained, the upper beam for the strain specimen is recorded and finally the lower beam strain specimen is recorded. The autocorrelation between the upper beam unstrained and strained specklegram is then calculated. The autocorrelation between the lower beam strain and unstrained specklegram is calculated. The difference in those two autocorrelation peak shifts is used to calculate the strain in the surface.

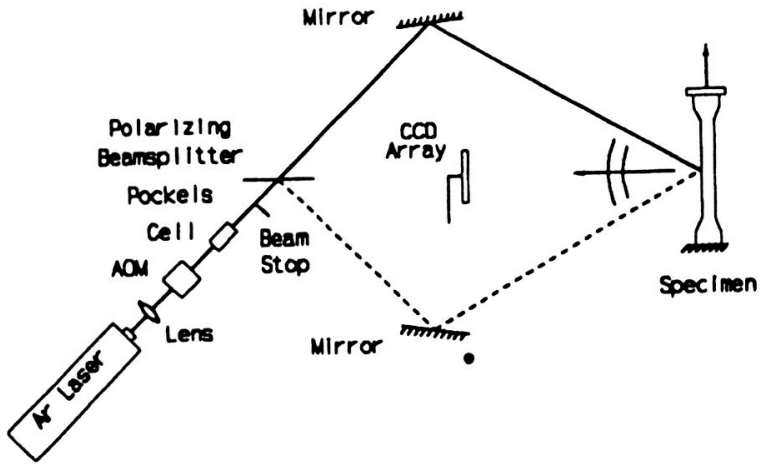

Figure 13. - Laser speckle strain measurement optical system. (Used by permission of C.T. Lant, Sverdrup Technology, Inc.) 
The speckle system has been demonstrated to measure the same strain levels as a resistance strain gage mounted on the opposite side of the specimen from the laser beam interaction. In figure 14 the resistant strain gage tracks very closely to the laser speckle strain system. The vertical shift is a result of the starting point for the two systems. Figure 15 shows the two principal strains for a two-dimensional strain measurement system measured with the specimen at $700^{\circ} \mathrm{C}\left(1300^{\circ} \mathrm{F}\right)$. The ratio of the two strain modula gives Poisson's ratio which is within the acceptable value of the materials measured.

A system based on this concept is being built which measures the strain in a fiber. Strain in tungsten fibers as small as $76 \mu \mathrm{m}$ has been measured. Also $150 \mu \mathrm{m}$ diameter saphikon fibers and $140 \mu \mathrm{m}$ diameter silicon carbide fibers have been measured. At present the fiber work has been limited to room temperature.

The laser speckle strain measurement system has been demonstrated in a tensile mode for tensile specimens up to

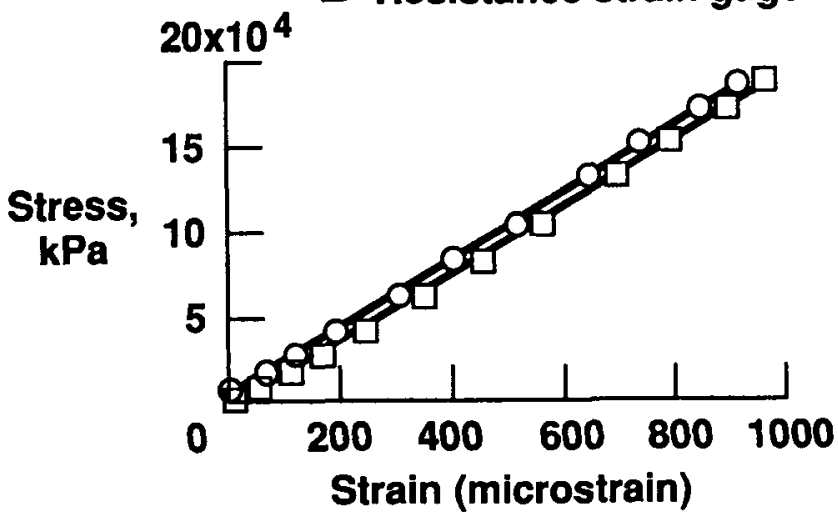

Figure 14. - Room temperature comparison with resistance strain gage. (Used by permission of C.T. Lant, Sverdrup Technology, Inc.)

\section{O Principal axis strain $\square$ Cross axis strain}

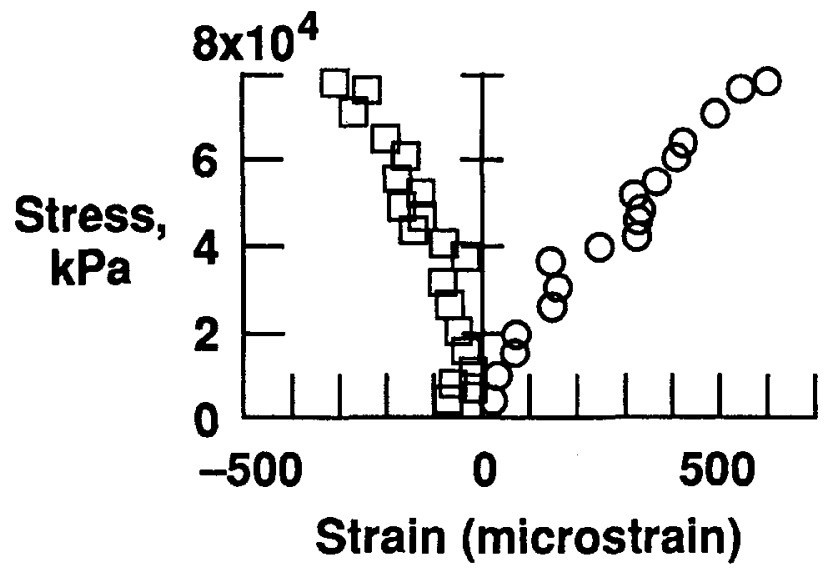

Figure 15 . - Two dimensional strain measurement at $700{ }^{\circ} \mathrm{C}$. (Used by permission of C.T. Lant, Sverdrup Technology, Inc.) some $700{ }^{\circ} \mathrm{C}$. There is no physical reason why this system could not measure strain in specimens to considerably higher temperatures. Stable speckle patterns have been demonstrated to $2500^{\circ} \mathrm{C}\left(4500^{\circ} \mathrm{F}\right)$ on a tungsten filament mounted in a light bulb. The light bulb prevented convection currents from the specimen from disrupting the optical path. The data in figure 15 at $700^{\circ} \mathrm{C}$ was recorded with a specimen inside an enclosure with a glass plate window which limited airflow over the specimen. Plans are for even higher temperature measurements. These systems have a typical strain resolution of about $15 \mu \mathrm{m}$ and can be used in the plastic region. However, this concept may be limited to a point measurement of strain.

\section{Phase-shifting Interferometry}

Phase-shifting interferometry is a remote measurement technique for whole specimen strain or displacement fields. It has been demonstrated at NASA Lewis Research Center, (refs. 14 and 15) with Case Western Reserve University. Phaseshifting interferometry is more properly called vector displacement phase shifting holographic interferometry, since it tracks the direction and magnitude of displacement of a surface. Phase-shifting interferometry is a technique similar to conventional holographic arrangement and therefore the optical system is similar (fig. 16). The fundamental differences between these two approaches is in the modulation of the reference beam and the recording of the intensity pattern with a CCD camera rather than the recording of a hologram. However, for ease of use a hologram is recorded and used as a reference. It includes a laser, spatial filters for both the object and reference beam, a beam splitter, and mirrors.

The phase shifting of the reference beam is accomplished with a piezoelectric translator driving the reference beam mirror under microcomputer control. The intensity pattern is measured with a CCD camera located after the hologram and converted to a digital signal by a frame grabbing board in the

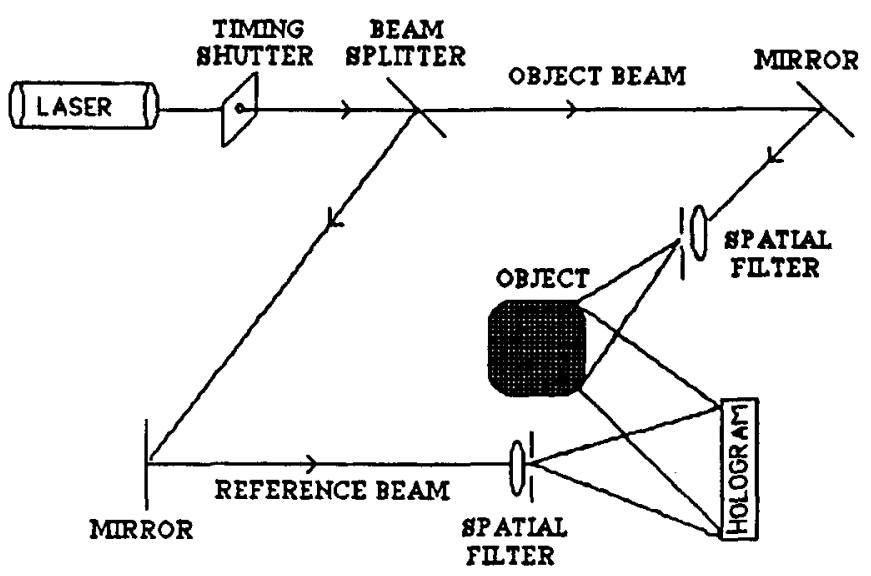

Figure 16. - Optical arrangement for the phase-shifting interferometry system for one camera operation. (Used by permission of B. Ovryn, Sverdrup Technology, Inc.) 
microcomputer. The $\mathrm{CCD}$ camera records the intensity image for a given reference mirror position. The phase information is determined by comparing images for different mirror positions. The phase difference information for the two stress states of the specimen is used to derive whole field strain.

To date a two dimensional system has been demonstrated. Extension measurements have been made to $5 \mathrm{~nm}$ corresponding to strain levels as small as a few microstrain (figs. 17 and 18). This was accomplished at temperatures of $600^{\circ} \mathrm{C}(1100$ ${ }^{\circ} \mathrm{F}$ ). At these temperatures there was almost no problems associated with convection currents, therefore it is believed that measurements at much higher temperatures are possible. The test temperature was limited by the laboratory hardware and no physical limitation has been identified.

While the technique was demonstrated for two dimensional displacements, adapting the concept to three dimensions is straightforward. This concept is the most promising of all remote systems for full field measurements.

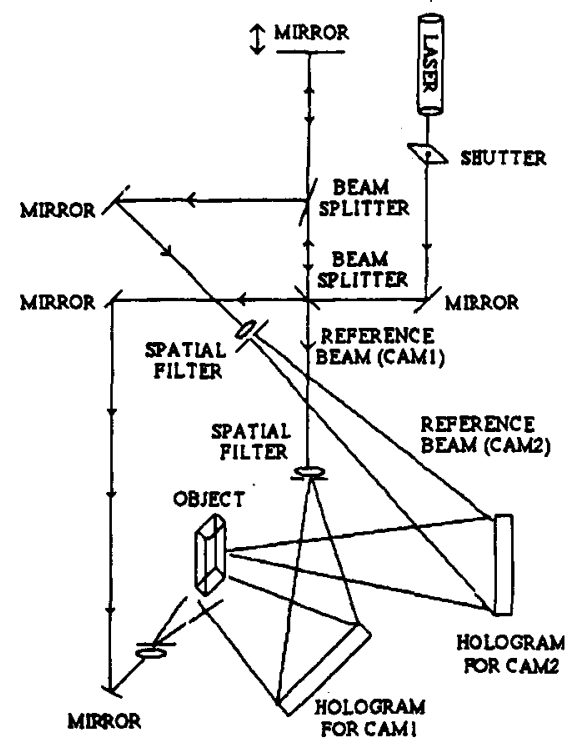

Figure 17. - Optical arrangement for the two camera phase-shifting interferometry system. (Used by permission of B. Ovryn, Sverdrup Technology, Inc.)

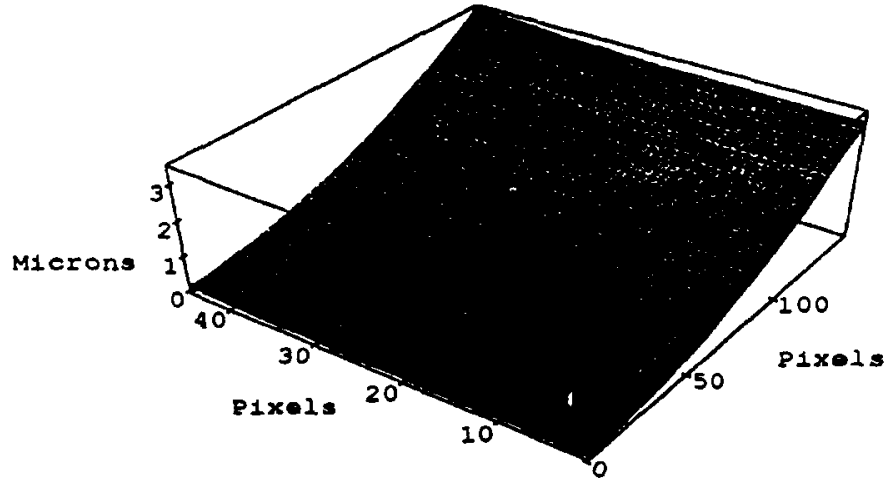

Figure 18. - Displacement plot versus pixel number of the camera. (Used by permission of B. Ovryn, Sverdrup Technology, Inc.)

\section{X-Ray Extensometry}

$\mathrm{X}$-ray extensometry is a completely new concept in the remote strain sensing field (ref. 16). It can be used on test articles at high temperatures and in hostile environments such as in the presence of airborne particles. Convection currents, smoke, flame, and other materials which might block or distort the path for optical systems present no problem for $\mathrm{x}$-ray based measurements.

The x-ray extensometer system (fig. 19) consists of an $x$ ray source, a bent crystal which focuses the $x$-ray beam into a narrow line beam and a fluorescent target or two which is attached to the specimen. A detector is placed in front of the specimen which measures secondary $\mathbf{x}$-rays from the fluorescing target. The bent crystal travels through an arc whose center is at the $x$-ray source. This causes the $x$-ray line image to scan over the fluorescing target. As the image begins to pass over the target the secondary $x$-rays intensity increases linearly until the image is completely on the target (fig. 20) where the number of the secondary $x$-rays is constant.

The system can be utilized to measure strain in a material by measuring the magnitude of the width between the rising and falling of the secondary $x$-ray counts. In this way the system is utilized either as an extensometer or as a strain gage if one knows the separation between target edges. The gage length is determined by the spacing between fluorescing targets or the spacing between the ends of one fluorescing target. This technique has been demonstrated to measure displacement on the order of $1.25 \mu \mathrm{m}$ and with strain resolution of $25 \mu \varepsilon$. With improved signals, a factor of ten improvements are possible.

While the original demonstration utilizes targets attached to the test article, the system can be completely noncontacting. The only requirement is a variation in $\mathrm{x}$-ray emitter on the surface. This may be accomplished by addition of or removal of material. It does not appear possible to modify the concept to make full field measurements.

\section{(OVERHEAD VIEW)}

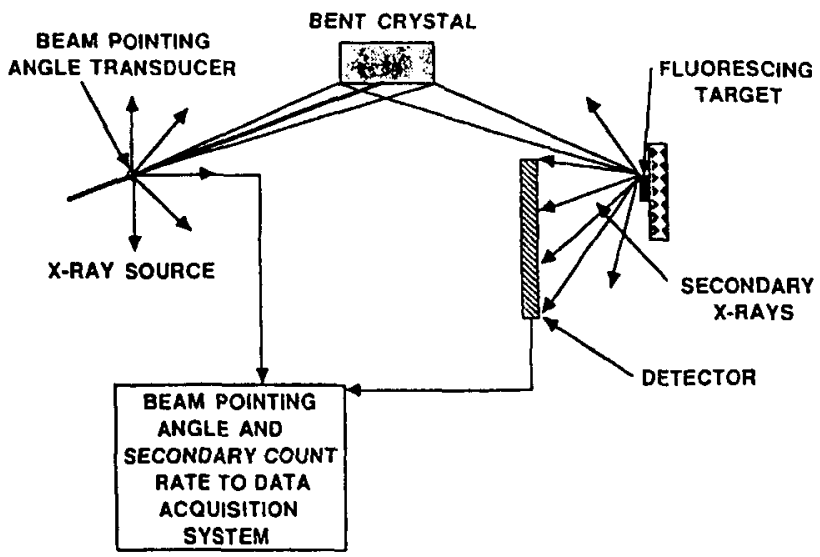

Figure 19. - Schematic view of a typical $x$-ray displacement measuring system. (Used by permission of $\boldsymbol{H}$. Canistraro, University of Connecticut.) 


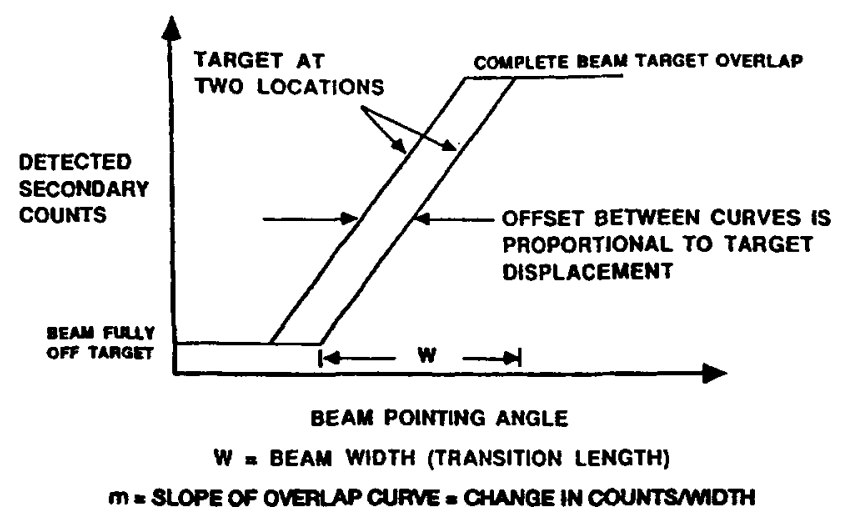

Figure 20. - A theoretical scan at two target positions. The offset between the two is proportional of target displacement. (Used by permission of $\mathbf{H}$. Canistraro, University of Connecticut.)

\section{Conclusions}

This paper reviewed the status of the six most promising high temperature strain sensors and systems. Three of these are resistance strain gages and three are remote techniques. Of the remote schemes two are optical and one $x$-ray based. The limitations of strain gages are a result of the lack of stability of strain gage alloys at high temperatures and large apparent strain. The PdCr gage and a new gage design called the LaRC compensated gage are addressing this problem. The BCL gage is being tested now as a compensated gage to reduce apparent strain. Every application of any gage on a different material still requires that a new apparent strain curve be recorded.

The development of remote strain sensing has promised many advancements and now some of those advancements are being realized. Remote techniques are moving from the laboratory into the test cell. Progress for optical techniques has been slow, since each concept requires significant software application, but uniform. Laser speckle is a point strain measurement concept usable to high temperature as long as the convection currents can be made small so that speckle correlation is not lost. Phase shifting interferometry is the concept with the most to offer in terms of full field and noncontacting. The concept has yet to be demonstrated at very high temperatures. The $\mathbf{x}$-ray based system is a very promising system for measuring strain in a harsh environment such as in a luminous flame.

\section{Acknowledgements}

The author wishes to acknowledge the following researchers who performed groundbreaking work in the areas of contact and remote strain sensing techniques and thanks them for the use of their data: Mike Lemcoe, Tom Moore, Jih-Fen Lei, Chris Lant, Larry Greer, Larry Oberle, John Barranger, Ben Ovryn, Eric Jordan, and Howard Canistraro. Also a special thanks to Art Decker, Norman Wenger and Jih-Fen Lei for reading the manuscript.

\section{References}

1. Lemcoe, M.M.: Development of High Temperature Strain Gages. NASA CR-112241, 1973.

2. Lemcoe, M.M.: Development of Strain Gages for Use to 1311 K (1900 degrees F). NASA CR-132485, 1974.

3. Lemcoe, M.M.: Characterization of BCL Strain Gages For Use to $1366 \mathrm{~K}$ (2000 degrees F). NASA CR-132739, 1975.

4. Lemcoe, M.M.: High-Temperature Strain Measurement Techniques: Current Developments and Challenges. The 1992 NASA Langley Measurement Technology Conference, NASA CP-3161, 1992, p. 127169.

5. Lemcoe, M.M.: Valid Resistance Strain Measurements to Temperatures Approaching 2000 F: Can lt Be Done? Presented at the Sensors Expo, Cleveland, OH, Sept. 1989.

6. Lei, J.-F.: The Apparent Strain Stability And Repeatability Of A BCL3 Resistance Strain Gage. NASA CR-187056, 1991.

7. Holmes, H.K.; and Moore, T.C. Sr.: High Temperature Strain Gage Apparent Strain Compensation. The 1992 Langley Measurement Conference, NASA CP-3161, 1992, pp. 211-222.

8. Wu, Z.-D.; and Ma, L.-C: Comparison of Characteristics of Our Temperature-Compensated Resistance Strain Gages for Use to $700^{\circ} \mathrm{C}$ and $800^{\circ} \mathrm{C}$. Annual Hostile Environments and High Temperature Measurements Conference, 4th; Proceedings, Society for Experimental Mechanics, Bethel, CT, 1987, pp. 30-34.

9. Hulse, C.O., et al.: High Temperature Static Strain Gage Development. NASA CR-189044, 1991.

10. Lei, J.F.: Palladium-Chromium Static Strain Gages For High Temperatures. The 1992 NASA Langley Measurement Technology Conference, NASA CP-3161, 1992, pp. 189-209.

11. Kobayashi, A.S., ed.: Handbook On Experimental Mechanics. PrenticeHall, Englewood Cliffs, NJ, 1987.

12. Yamaguchi, I.: A Laser-Speckle Strain Gauge: J. Phys. E., vol. 14, no. 11, 1981, pp. 1270-1273.

13. Lant, C.T.: Laser-Based Strain Measurements for High Temperature Applications. The 1992 NASA Langley Measurement Technology Conference, NASA CP-3161, 1992, pp. 245-249.

14. Ovryn, B.: Two Caremera Face Measurements Using Fase Stepped RealTime Holographic Interferometry. To be published in Holography, Interferometry, and Optical Pattern Recognition in Biomedicine III, SPIE Proceedings, Vol. 1889, 1993.

15. Ovryn, B.: Measurement of Object Displacement Using Phase Stepped, Real-Time Holographic Interferometry. Ph.D. Thesis, Case Western Reserve University, Cleveland, OH, 1992.

16. Canistraro, H.A., et al.: X-Ray Based Displacement Measurement for Hostile Environments. NASA TM-105551, 1992. 


\begin{tabular}{|c|c|c|}
\hline \multicolumn{2}{|c|}{ REPORT DOCUMENTATION PAGE } & $\begin{array}{l}\text { Form Approved } \\
\text { OMB No. 0704-0188 }\end{array}$ \\
\hline \multicolumn{3}{|c|}{ 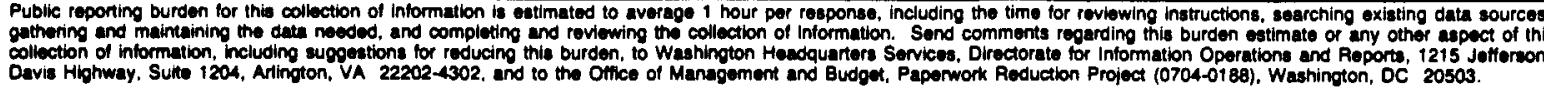 } \\
\hline 1. AGENCY USE ONLY (Leavo blank) & \begin{tabular}{|l} 
2. AEPORT DATE \\
August 1993
\end{tabular} & $\begin{array}{l}\text { D DATES COVEAED } \\
\text { echnical Memorandum }\end{array}$ \\
\hline \multicolumn{2}{|c|}{$\begin{array}{l}\text { 4. TIRE AND BUBTTLE } \\
\text { Strain Sensing Technology for High Temperature Applications }\end{array}$} & 5. FUNDING MUMBERS \\
\hline \multicolumn{2}{|l|}{$\begin{array}{l}\text { 6. AUTHOR(S) } \\
\text { W. Dan Williams }\end{array}$} & WU $-505-62-50$ \\
\hline \multicolumn{2}{|c|}{$\begin{array}{l}\text { National Aeronautics and Space Administration } \\
\text { Lewis Research Center } \\
\text { Cleveland, Ohio } 44135-3191\end{array}$} & $\begin{array}{l}\text { 8. PEAFORMING ORGAMIZATION } \\
\text { REPORT MUMBER } \\
\text { E-7650 }\end{array}$ \\
\hline \multicolumn{2}{|c|}{$\begin{array}{l}\text { National Aeronautics and Space Administration } \\
\text { Washington, D.C. 20546-0001 }\end{array}$} & $\begin{array}{l}\text { 10. SPONSORIMG/MONTOANG } \\
\text { AOENCY REPORT NUMBER } \\
\text { NASA TM-4498 }\end{array}$ \\
\hline \multicolumn{3}{|l|}{ 11. SUPPLEMENTARY NOTES } \\
\hline \multicolumn{3}{|c|}{$\begin{array}{l}\text { Prepared for the AIAA 4th International Aerospace Planes Conference, Orlando, Florida, December 1-4, } 1992 . \\
\text { Responsible person, W. Dan Williams, (216) 433-3725. }\end{array}$} \\
\hline \multicolumn{2}{|c|}{ 122. DISTRIDUTION/AVAILABILTTY STATEMENT } & 12b. DISTRIBUTION CODE \\
\hline
\end{tabular}

\section{Asstract Reximum 200 worde)}

This review paper discusses the status of strain sensing technology for high temperature applications. Technologies covered are those supported by NASA such as required for applications in hypersonic vehicles and engines, advanced subsonic engines, as well as material and structure development. The applications may be at temperatures of $540^{\circ} \mathrm{C}\left(1000^{\circ} \mathrm{F}\right)$ to temperatures in excess of $1400^{\circ} \mathrm{C}\left(2500^{\circ} \mathrm{F}\right)$. The most promising technologies at present are the resistance strain gage and remote sensing schemes. Resistance strain gages discussed include the BCL gage, the LaRC compensated gage, and the $\mathrm{PdCr}_{\mathrm{g}}$ gage. Remote sensing schemes such as laser based speckle strain measurement, phase-shifting interferometry and $\mathrm{X}$-ray extensometry will be discussed. Present status and limitations of these technologies are presented.

\begin{tabular}{|c|c|c|c|}
\hline \multirow{2}{*}{\multicolumn{3}{|c|}{$\begin{array}{l}\text { 14. BUEJECT TERm8 } \\
\text { Strain sensing; High temperature; Measurements }\end{array}$}} & \multirow{2}{*}{$\begin{array}{c}\text { 15. NULEEA OF PAOES } \\
12 \\
\begin{array}{c}16 . \text { PAKCE CODE } \\
\text { A03 }\end{array} \\
\end{array}$} \\
\hline & & & \\
\hline $\begin{array}{l}\text { 17. BECURTY CLASSAFICATION } \\
\text { OF REPOAT } \\
\text { Unclassified }\end{array}$ & $\begin{array}{l}\text { 16. 8ECURTY CLABSIFICATION } \\
\text { OF TMES PAOE } \\
\text { Unclassified }\end{array}$ & $\begin{array}{l}\text { 19. SECUATY CLASBIFICATIOH } \\
\text { OF ABStRACT } \\
\text { Unclassified }\end{array}$ & 20. LUMTATION OF ABSTRACT \\
\hline NSN 754 & & CLE: IY9s & $\begin{array}{l}\text { Idard Form } 298 \text { (Rov. 2-89) } \\
\text { orioed by AN81 Std. Z39-18 } \\
102\end{array}$ \\
\hline
\end{tabular}

